\title{
Sjögren's syndrome and mean platelet volume
}

\author{
M.E. Tezcan', S̨. Demir², M. Sargın², M. Aliustaoğlu', B. Göker ${ }^{4}$ \\ ${ }^{1}$ Rheumatology Consultant, Kartal Training and Research Hospital, Istanbul, Turkey; \\ ${ }^{2}$ Department of Family Practice, Kartal Training and Research Hospital, Istanbul, Turkey; \\ ${ }^{3}$ Department of Internal Medicine and Oncology, Kartal Training and Research Hospital, Istanbul, Turkey; \\ ${ }^{4}$ Department of Rheumatology, Gazi University Faculty of Medicine, Ankara, Turkey
}

\section{Letter to the Editor}

Sirs,

The mean platelet volume (MPV) is a parameter indicating the average size of blood platelets (1). The association between MPV and rheumatic diseases, such as systemic sclerosis (2), familial Mediterranean fever (3), rheumatoid arthritis (4), ankylosing spondylitis (5) and Behçet's disease (6) has been previously reported. In Sjögren's syndrome (SS), acute phase reactants are not included in the activity indexes, such as Sjögren's syndrome disease activity index (SSDAI) and Sjögren's systemic clinical activity index $(7,8)$. Therefore, reliable parameters correlating with disease activity are needed. In this study, we aimed to investigate the significance of MPV as an inflammatory marker in SS. We compared MPV of SS patients with those of healthy controls and studied correlations between MPV and SS disease activity.

Forty-two patients with primary SS (PSS), diagnosed according to the 2012 American College of Rheumatology Sjögren Classification Criteria (9), and 32 healthy volunteers were enrolled. SSDAI was used to determine SS activity (7). The study protocol was approved by the Local Research Ethical Committee. The Statistical Package for Social Sciences (SPSS; IBM Corp., Armonk, NY, USA) version 17.0 was used. All data were expressed as mean \pm standard deviation and $\mathrm{P}$ values $<0.05$ were considered statistically significant.

Table I shows demographic features, clinical activity scores and laboratory findings. These parameters did not differ between PSS patients and healthy controls, except for MPV and erythrocyte sedimentation rate (ESR).

Clinical features of patients with SS are reported in Table II. None of the patients had a SSDAI score $>5$.

MPV values of PSS patients were higher than those of the control group (11.26 \pm 0.92 fL vs 9.30 $\pm 1.83 \mathrm{fL} ; \mathrm{P}=0.002$ ). PSS patients

Table I - Demographic and laboratory features of study and control groups.

\begin{tabular}{|l|l|l|l|}
\hline & PSS $(\mathbf{n}=42)$ & Control $(\mathbf{n}=32)$ & P \\
\hline Age $($ year) & $49.75 \pm 10.60$ & $48.31 \pm 11.34$ & 0.616 \\
\hline Gender $(\mathrm{M} / \mathrm{F})$ & $2 / 42$ & $1 / 31$ & 0.080 \\
\hline ESR $(\mathrm{mm} / \mathrm{h})$ & $35.74 \pm 22.84$ & $14.81 \pm 5.13$ & 0.001 \\
\hline CRP $(\mathrm{mg} / \mathrm{dL})$ & $4.56 \pm 4.07$ & $3.5 \pm 2.04$ & 0.452 \\
\hline WBC $(\mathrm{x} 103 / \mathrm{mL})$ & $7.44 \pm 3.27$ & $6.71 \pm 1.64$ & 0.501 \\
\hline PLT $(\mathrm{x} 103 / \mathrm{mL})$ & $250.77 \pm 105.64$ & $255.18 \pm 67.86$ & 0.892 \\
\hline MPV $(\mathrm{fL})$ & $11.26 \pm 0.92$ & $9.30 \pm 1.53$ & 0.002 \\
\hline Hb $(\mathrm{g} / \mathrm{dL})$ & $12.64 \pm 1.11$ & $13.39 \pm 1.00$ & 0.060 \\
\hline SSDAl & $1.44 \pm 1.54$ & - & - \\
\hline
\end{tabular}

ESR, erythrocyte sedimentation rate; CRP, C-reactive protein; WBC, white blood cell; PLT, platelet count; MPV, mean platelet volume; Hb, hemoglobin; SSDAI, Sjögren's syndrome disease activity index.

Corresponding author: Mehmet Engin Tezcan Rheumatology Consultant Kartal Training and Research Hospital Semsi Denizer Street 34865 Kartal, Istanbul, Turkey E-mail: engintez@yahoo.com 
Table II - Disease features of patients having primary Sjögren's syndrome.

\begin{tabular}{|l|l|}
\hline Features & Patients N (\%) \\
\hline ANA & $34(80.9)$ \\
\hline Anti-SSA & $26(61.9)$ \\
\hline Anti-SSB & $14(33.3)$ \\
\hline RF & $23(54.7)$ \\
\hline $\begin{array}{l}\text { Salivary gland biopsy focus score } \geq \\
1 / 4 \text { mm2 }\end{array}$ & $42(100.0)$ \\
\hline Ocular staining score $\geq 3$ & $31(73.8)$ \\
\hline Arthritis & $28(66.6)$ \\
\hline $\begin{array}{l}\text { Extraglandular involvement except } \\
\text { arthritis }\end{array}$ & $2(4.7)$ \\
\hline ANA, antinuclear antibody; RF, rheumatoid factor.
\end{tabular}

had higher ESR compared to the control group $(35.74 \pm 22.84 \mathrm{~mm} / \mathrm{h}$ vs $14.81 \pm 5.13$ $\mathrm{mm} / \mathrm{h} ; \mathrm{P}=0.01)$. Neither MPV $(\mathrm{P}=0.253)$ nor ESR $(\mathrm{P}=0.466)$ nor $\mathrm{C}$-reactive protein $(\mathrm{P}=0.133)$ of PSS patients correlated with the SSDAI scores.

Our findings suggest that MPV is higher in PSS compared with controls, although it does not seem to correlate with SS disease activity. MPV could be an indicator of platelet turnover. In patients with a rapid turnover, MPV will be higher because of the larger size of newly produced platelets (10). Immune-mediated platelet lysis with the contribution of B-cell activating factor that is increased in the serum of SS patients may be one mechanism (11). As a result, mild platelet destruction and concomitant increased thrombopoiesis with or without thrombocytopenia may be the reason for increased MPV in PSS. The major limitations of this study are the small number of patients and the low SS disease activity. In conclusion, MPV was found higher in PSS patients and uncorrelated with disease activity. Further studies evaluating PSS patients with higher disease activity and extra-glandular system involvement are needed to assess the clinical utility and validity of MPV.

Contributions: the authors contributed equally.
Conflict of interest: the authors declare no potential conflict of interest.

\section{REFERENCES}

1. Giles C. The platelet count and mean platelet volume. Br J Haematol. 1981; 48: 31-7.

2. Soydinc S, Turkbeyler IH, Pehlivan Y, Soylu G, Goktepe MF, Bilici M, et al. Mean Platelet volume seems to be a valuable marker in patients with systemic sclerosis. Inflammation. 2014; 37: 100-6.

3. Makay B, Turkyilmaz Z, Unsal E. Mean platelet volume in children with familial Mediterranean fever. Clin Rheumatol. 2009; 28: 975-8.

4. Milovanovic M, Nilsson E, Jaremo P. Relationships between platelets and inflammatory markers in rheumatoid arthritis. Clin Chim Acta. 2004; 343: 237-40.

5. Kisacik B, Tufan A, Kalyoncu U, Karadag O, Akdogan A, Ozturk MA, et al. Mean platelet volume (MPV) as an inflammatory marker in ankylosing spondylitis and rheumatoid arthritis. Joint Bone Spine. 2008; 75: 291-4.

6. Ekiz O, Balta I, Sen BB, Rifaioglu EN, Ergin $\mathrm{C}$, Balta $\mathrm{S}$, et al. Mean platelet volume in recurrent aphthous stomatitis and behcet disease. Angiology. 2014; 65: 161-5.

7. Barry RJ, Sutcliffe N, Isenberg DA, Price E, Goldblatt F, Adler M, et al. The Sjogren's syndrome damage index - a damage index for use in clinical trials and observational studies in primary Sjogren's syndrome. Rheumatology (Oxford). 2008; 47: 1193-8.

8. Bowman SJ, Sutcliffe N, Isenberg DA, Goldblatt F, Adler M, Price E, et al. Sjogren's systemic clinical activity index (SCAI) - a systemic disease activity measure for use in clinical trials in primary Sjogren's syndrome. Rheumatology (Oxford). 2007; 46: 1845-51.

9. Shiboski SC, Shiboski CH, Criswell L, Baer A, Challacombe S, Lanfranchi H, et al. American College of Rheumatology classification criteria for Sjogren's syndrome: a data-driven, expert consensus approach in the Sjogren's International Collaborative Clinical Alliance cohort. Arthritis Care Res (Hoboken). 2012; 64: 475-87.

10. Kottke-Marchant K. Platelet disorders. In: E.D. Hsi, ed. Hematopathology. $2^{\text {nd }}$ ed. Philadelphia, PA: Elsevier-Saunders; 2012; 55-98.

11. Mariette X, Roux S, Zhang J, Bengoufa D, Lavie F, Zhou T, et al. The level of BLyS (BAFF) correlates with the titre of autoantibodies in human Sjogren's syndrome. Ann Rheum Dis. 2003; 62: 168-71. 